\title{
CORRIGENDA AND ERRATA
}

\section{Corrigendum: Sequence elements outside the hammerhead ribozyme catalytic core enable intracellular activity}

Anastasia Khvorova, Aurélie Lescoute, Eric Westhof \& Sumedha D Jayasena

Nat. Struct. Biol. 10, 708-712 (2003).

Figure 4e in this paper contained mistakes. The labels for the fourth, fifth and sixth sets of data should be sTRSV + PL1, sTRSV + PL2 and sTRSV + PL1\&2, respectively. We apologize for the inconvenience this may have caused.

\section{Erratum: Pulling geometry defines the mechanical resistance of a $\beta$-sheet protein}

David J Brockwell, Emanuele Paci, Rebecca C Zinober, Godfrey S Beddard, Peter D Olmsted, D Alastair Smith, Richard N Perham \& Sheena E Radford

Nat. Struct. Biol. 10, 731-737 (2003).

A mistake was introduced during production of this paper. This mistake was on page 731, line 4 of the second paragraph in the 'Results' section. The correct sentence should read: "The parent (I27) ${ }_{5}$ homopolymer has been described and is composed of five copies of a mutated C47S C63S domain $^{7,12}$." We apologize for any inconvenience this may have caused. 